\title{
Investigations into the Elemental Composition of Earthenware Vessels from the Guthe Collection using Instrumental Neutron Activation Analysis
}

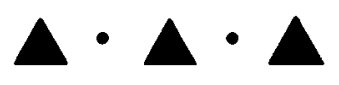

ALICE YAO

INTRODUCTION: LOCAL EARTHENWARE VESSELS OF THE CENTRAL VISAYANS

IMPORTANT TO THE GROWTH of chiefdom polities in the Philippines is the expansion of internal trade between coastal and inland groups (Bacus 1990:349-350; Junker 1999:262). Ethnohistorical and archaeological evidence indicate that earthenware pottery manufactured by lowland coastal potters was one of the primary products traditionally exchanged between coastal and inland groups. While the increasing value placed on import ceramics (porcelain and celadon) and their role in the political economy has been well documented, local dimensions of production and internal trade are also important to an understanding of the political economy. Specifically, the organization of local pottery production may have changed to accommodate the development and consolidation of alliances between coastal and interior groups, as Junker (1999) discovered in the Tanjay chiefdom (264). During the height of Tanjay's power, which spanned the early to mid second millennium AD, growing status stratification between elites spurred an expansion in regional earthenware exchange (Junker 1999:290-291). Earthenware were not only functional domestic vessels but also facilitated feasts and public gatherings held by chiefs. Control over the manufacture and distribution of these wares was thus economically important to the creation of political alliances and subjects.

The identification of compositional groups within local earthenware assemblages presents a potential means to the evaluation of exchange and production systems. Junker's (1990) study of temper and morphology of earthenware represented a seminal approach to the detection of local versus non-local ware. More recently, Niziolek (2013) used laser ablation-inductively coupled plasma-mass spectrometry (LA-ICPMS) to identify differences in clay composition in the Bais-Tanjay region of Negros Island. Her analysis indicate that earthenware production was organized as both as a non-specialized and full-time centralized craft in the Tanjay polity. In this article, I undertake a preliminary investigation of earthenware production and distribution by conducting instrumental neutron activation analysis (INAA) on earthenware samples 

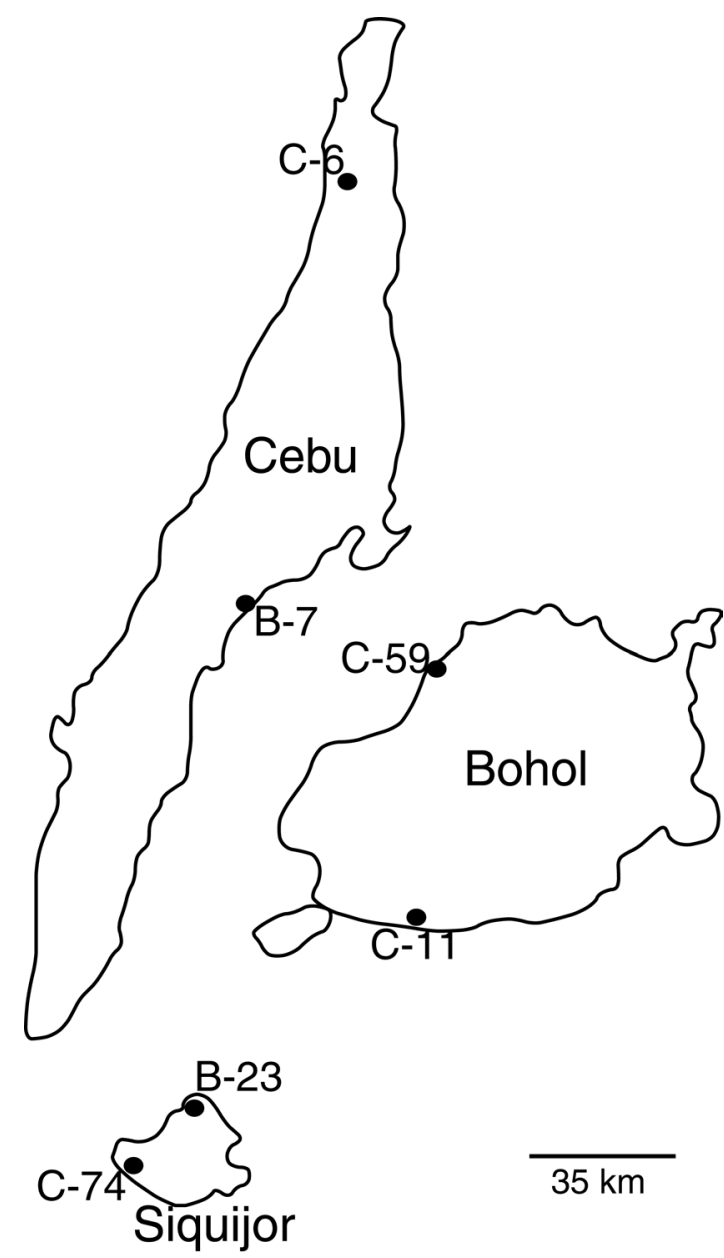

Fig. 1. Map of the study area and approximate site locations (after Guthe 1929).

that Guthe collected from adjacent island polities considered to be contemporaneous with Tanjay. The detection of compositional patterns in the earthenware assemblage from the Visayan region may help identify distinct production groups. It must be acknowledged that a pilot study of this kind may not achieve sufficient resolution to identify elemental groupings, but anticipates the chemical profiles generated will serve as a valuable reference material for future studies in this part of the world.

\section{GEOGRAPHICAL AND GEOLOGICAL BACKGROUND}

The islands of Cebu, Bohol, and Siquijor, located in the Visayan region, serve as the area of study (Fig. 1). Accounts of craft production exist for the Cebu chiefdom, but mainly refer to full-time specialization in iron, metal goods, and textile production, and not in utilitarian items such as earthenware (Junker 1999:267). In addition to the tradeware, Guthe also collected samples of whole and incomplete earthenware vessels.

A critical initial step in the evaluation of clay composition is an understanding of the regional geologic history to determine the possible elemental representation in 
the raw material. The earliest deposits on Cebu, Bohol, and Siquijor date from the Palaeocene-Eocene period (Philippine Geological Survey Division 1963). Geologic description for the region is most comprehensive for Cebu, which often serves as a generalization for the Visayan region (Smith 1924:195). A comparison of the geologic formation for the region suggests the interior of the islands consists of a fairly consistent distribution with igneous and volcanic rocks, largely from the PalaeoceneEocene period. From the intermediary uplands to the coastal areas, more recent formations of sedimentary and metamorphic material are typical.

According to Smith's (1924) description, the central cordillera (interior mountains) of Cebu are comprised mainly of igneous and metamorphic material where diorite is the basal complex rock (99). The chief characteristic of the diorites is the considerable amount of hornblende and feldspar with a predominance of plagioclase (98). True granite is a rare rock in the Philippines; Smith (1924) suggests that the "granites" in the cordillera region conform more closely to the composition of grano-diorite type (102). The remainder of the island extending from the mesetas or "little table lands" (between the cordillera and intermediate uplands) to the coast is characterized by limestone, sandstone, arkose, and tuffic material (191). Unfortunately, the precise mineral contents of these clastic formations are of a fragmentary nature for the island. Smith's petrographic analysis of one Cebu arkose specimen shows a composition rich in feldspar mineral (orthoclase) and little biotite and olivine, suggesting weathering from interior dioritic materials. The coastal plains are also covered with alluvial deposits.

\section{SAMPLE SELECTION}

Because this pilot project allowed for 24 samples to be submitted for INAA, only a limited number of potsherds from each island could be tested. Attempt was made to

Table i. Relative Site Dates and Locations

\begin{tabular}{|c|c|c|c|}
\hline SITE & SAMPLE SIZE & DATE & DIAGNOSTIC POTSHERD \\
\hline $\begin{array}{l}\text { C59 Barrio Ta-oran Inabanga, } \\
\text { Bohol }\end{array}$ & 1 & Unknown & \\
\hline C11 Sucgan Cave Loay, Bohol & 8 & $\begin{array}{l}\text { 13th-15th centuries } \\
\text { A.D. }\end{array}$ & $\begin{array}{l}\text { Chinese celadon, porcelain, } \\
\text { and dragon jar }\end{array}$ \\
\hline B7 Barrio Naga Cebu, Cebu & 3 & $\begin{array}{l}\text { mid-14th-16th } \\
\text { centuries A.D. }\end{array}$ & $\begin{array}{l}\text { Chinese celadon and } \\
\text { porcelain }\end{array}$ \\
\hline C6 Calavera, Cebu & 4 & $\begin{array}{l}\text { 13th-15th centuries } \\
\text { A.D. }\end{array}$ & Dragon jars \\
\hline $\begin{array}{l}\text { B23 Barrio Sulangon San } \\
\text { Juan, Siquijor }\end{array}$ & 7 & 11th-(?) century A.D. & White stoneware and iron \\
\hline $\begin{array}{l}\text { C74 Barrio Maite San Juan, } \\
\text { Siquijor }\end{array}$ & 1 & $\begin{array}{l}11 \text { th }(?)-15 \text { th } \\
\text { centuries A.D. }\end{array}$ & Iron knife and porcelain* \\
\hline
\end{tabular}

Notes: Guthe based site locations on the nearest barrio (district) in each municipality. Bacus (1995 : 185200) provided a detailed summary of Guthe's descriptions of the physical surroundings and archaeological finds associated with individual sites. 
select an equal number of sites and number of samples from each of the adjoining islands of Bohol, Cebu, and Siquijor (Table 1). The sample intended to capture compositional variability of a known type within a defined spatio-temporal context. With the exception of complete earthenware vessels, the selection process screened potsherds based on two criteria: datable contexts and diagnostic vessel forms. Chronological dates were determined for each site based on relative cross-dating with the presence of tradeware and iron implements (Table 1). ${ }^{1}$ The sample is represented by two sites from each island and seven to nine potsherds from each site, with the exception of sites C-59 and C-74, which each only produced one due to the limited availability of diagnostic potsherds.

Following the morphological typology developed by Junker (1990) and Bacus (1995) for prehistoric earthenware and Guthe's annotated notes on the individual artifacts, samples were classified as globular shaped pots for cooking, shallow bowlshaped vessels, or restricted jar-like vessels (Bacus 1995:263). Most of the utilitarian earthenware in this sample are of the globular cooking pot type, given their greater occurrence as grave goods in the mortuary context. Shallow bowl-shaped vessel and jar-like vessel types were also included in the study to account for further possible variation. Table 2 is a detailed listing of the samples. Illustrations of the samples are shown in Figures 2 through 4.

The small sample size and the wide range of variation in site location certainly raise concerns about achieving the elemental resolution necessary to detect grouping. However, given the sample limit of this project and the preliminary nature of the investigation where no elemental library was available for the region, I chose to follow this selection criterion.

\section{METHODS}

The use of INAA in elemental analysis of archaeological materials has emerged as a significant technique because of its great sensitivity and resolution, especially in comparison with other available techniques. Given the geologic and cultural variability of clay composition encountered in this study, the large suite of elements and concentration levels (ppb) analyzable by INAA make it a particularly appropriate application. Specifically, slight differences in elemental composition and/or concentration levels can have important implications about provenance. For a thorough discussion on the principles of activation analysis, see Kruger (1971) and Muecke (1980).

Contaminants were cleaned off the surface of each potsherd with a carbide bit and sherds were washed with distilled water. Then, the sample was pulverized with a mortar and pestle and subsequently dried in an oven for 48 hours. One hundred fifty $\mathrm{mg}$ of the sample was then measured out with an allowable difference of $10 \mathrm{mg}$ and encapsulated in high-quality quartz tubes. One hundred fifty $\mathrm{mg}$ of standards (NIST $1633 \mathrm{~A} ; \mathrm{N}=3$ ) and check standards (NIST 1633b Ohio Red Clay; $N=2$ ) were weighed out. In addition, one blank was included. Irradiation was undertaken in the Ford Nuclear Reactor (FNR) and two counts were taken (Batch \#R935-01-1Q), the initial at 5 weeks and the second at 10 weeks.

The elements analyzed include predominantly the most precise on both reference materials with coefficients of variation typically less than 5 percent. Remaining elements that were less precise on one or both standards were also included. FNR values were further corroborated against University of Missouri-Columbia Research 
Table 2. Sample List and Description

\begin{tabular}{|c|c|c|c|c|}
\hline SAMPLE \# & ARTIFACT \# & ISLAND & CATALOG \# & DESCRIPTION \\
\hline AY1 & C-11-382 & Bohol & 48992 & $\begin{array}{l}\text { Everted rim of possible globular vessel with cord } \\
\text { impression }\end{array}$ \\
\hline AY2 & C-11-382 & Bohol & 48739 & Body potsherd of possible globular vessel \\
\hline AY3 & C-11-382 & Bohol & 48994 & Everted rim globular vessel \\
\hline AY4 & C-11-382 & Bohol & 48741 & Body potsherd from globular vessel \\
\hline AY5 & C-59-3 & Bohol & & Inverted rim from a restricted vessel \\
\hline AY6 & C-11-383 & Bohol & 48977 & Everted rim with neck of globular vessel \\
\hline AY7 & C-11-383 & Bohol & 48978 & Everted rim of globular vessel \\
\hline AY8 & C-11-383 & Bohol & 48970 & Everted rim of globular vessel \\
\hline AY9 & B-7-21b & Cebu & & Everted rim and body of globular vessel \\
\hline AY10 & B-7-19 & Cebu & & Inverted rim of unrestricted vessel "shallow bowl" \\
\hline AY11 & B-7-21a & Cebu & & Everted rim of globular vessel \\
\hline AY12 & C-6-a & Cebu & & Inverted rim from vessel of simple restricted shape \\
\hline AY13 & C-6-d & Cebu & & Everted "lipped" rim of restricted vessel \\
\hline AY14 & C-6-b & Cebu & & Everted "lipped" rim of restricted vessel \\
\hline AY15 & $\mathrm{C}-6-\mathrm{c}$ & Cebu & & Everted "lipped" rim with neck of restricted vessel \\
\hline AY16 & C-11-383 & Bohol & 48971 & Everted rim with neck of globular vessel \\
\hline AY17 & B-23-10e & Siquijor & 48675 & Everted rim from globular vessel \\
\hline AY18 & B-23-10d & Siquijor & 48675 & Body potsherd of globular vessel \\
\hline AY19 & B-23-10c & Siquijor & 48675 & Everted rim from restricted vessel \\
\hline AY20 & B-23-10b & Siquijor & 48675 & Base fragment from jar vessel \\
\hline
\end{tabular}

Note: Some artifacts have catalog numbers while others have field numbers, following the cataloging conventions used in the collection.

Reactor Center (MURR) values to verify for accuracy. Table 3 shows the elements analyzed in this study and the elemental output for individual samples is provided in Appendix 1.

The decision of which elements to analyze, as discussed above, was largely dependent on the precision of the detection values. Elements that have decayed beyond detection limits were further excluded because of the missing values. For elements where there was more than one energy line $(B a)$, cross-checking and evaluation against the reactor's log for the two energy lines determined the accuracy of the line. Further concern over which elements to use stemmed from negative detection counts, probably due to the extent of elemental decay. In these instances $(R b, S r, T a, T b, C s$, 

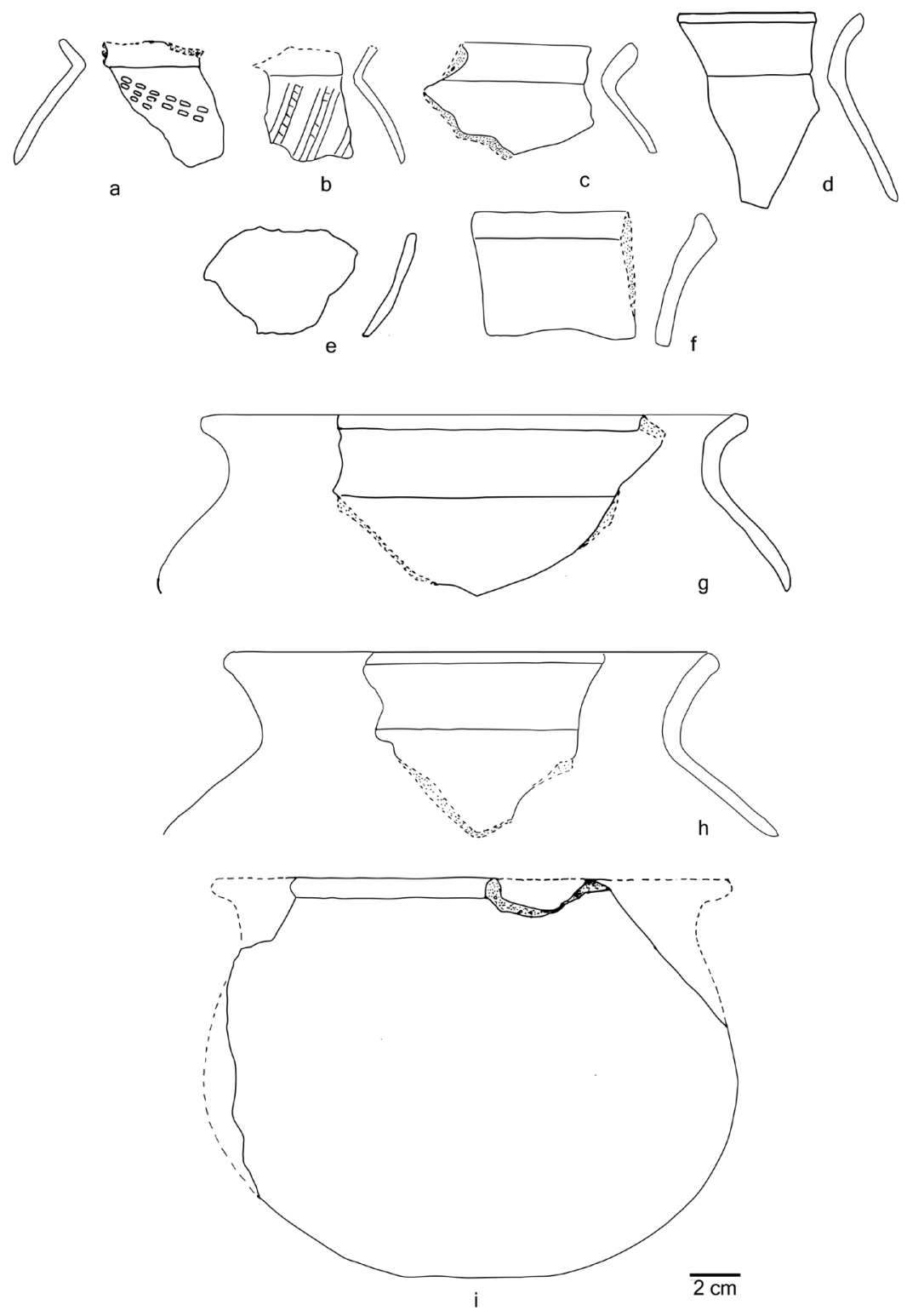

Fig. 2. Earthenware potsherds from the island of Bohol. Clockwise from left-a: AY03; b: AY01; c: AY05; d: AY07; e: AY02; f: AY05; g: AY16; h: AY08; and i: AY04.

$S b, K)$, where the difference between the negative value and the smallest positive value was close, I changed the negative value to a positive one. However, for those elements in which the difference between the negative and smallest positive value was great, I excluded the element from analysis $(\mathrm{Sr})$.

Certain elements were of greater interest to this study given the geologic information known about the specific areas. In particular, in the alkali group, elements such as $N a, K, B a$, and $R b$, which are associated with feldspar minerals, could yield 


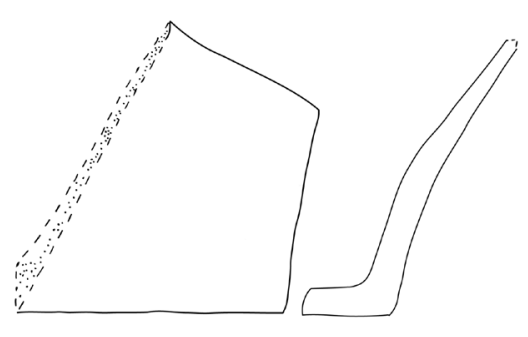

a

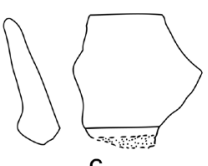

C

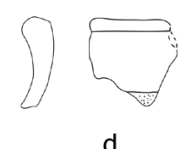

d

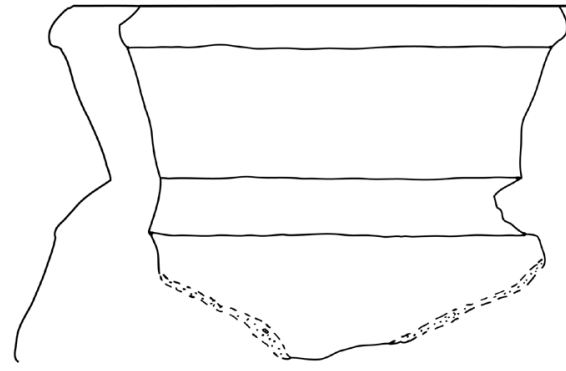

b

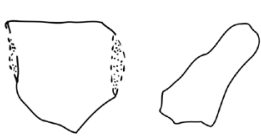

e

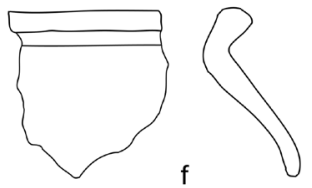

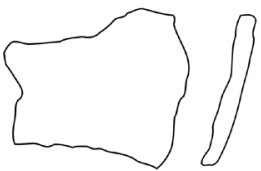

g

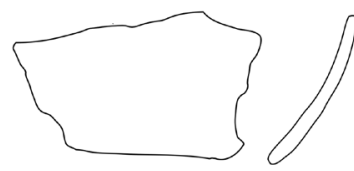

$\mathrm{h}$

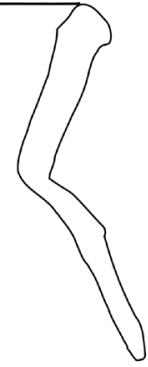

$\overline{2 \mathrm{~cm}}$

Fig. 3. Earthenware potsherds from the island of Siquijor. Clockwise from left-a: AY24; b: AY21; c: AY20; d: AY17; e: AY19; f: AY22; g: AY23; and h: AY18.

differential concentrations that may be significant at identifying compositional groups. The first transition metal $S c$ is equally critical to this study because differential concentrations may similarly identify distinctive clay sources and offer a description of production groups.

\section{RESULTS}

Preliminary bivariate plots for alkali elements and transition metals show no clear separation between the sites, presenting a distribution pattern that was rather interdispersed (see Figure 5). Instead of focusing on separation at the site level, the following bivariate analysis attempted to look for differentiation in the overall assemblage since our sample size for each site may have been too small to provide sufficient resolution. Preliminary group separations observed in bivariate plots were subsequently examined in multivariate space using cluster analysis. I chose to use hierarchical clustering and the Ward linking algorithm for the cluster analysis, a method that evaluates the homogeneity of clusters by minimizing the total sum of squared deviations from the mean (the error sum of squares or ESS) (Shennan 1997). If sufficient distance measures showing dissimilarity could be determined in the dendrogram, then I accepted the preliminary groupings and coded the groups. Confidence interval ellipses (set at 95\% level) were then fitted to confirm group membership. If the ellipses for each group did not overlap, then I interpreted this as confirmation of the individual observation's membership in the group, or 95 percent probability of where the distribution is expected to lie.

Group separation is strongest for two elements in the alkali group: Na and Ba496. Bivariate analysis for other suites of did not produce clear and consistent patterns 

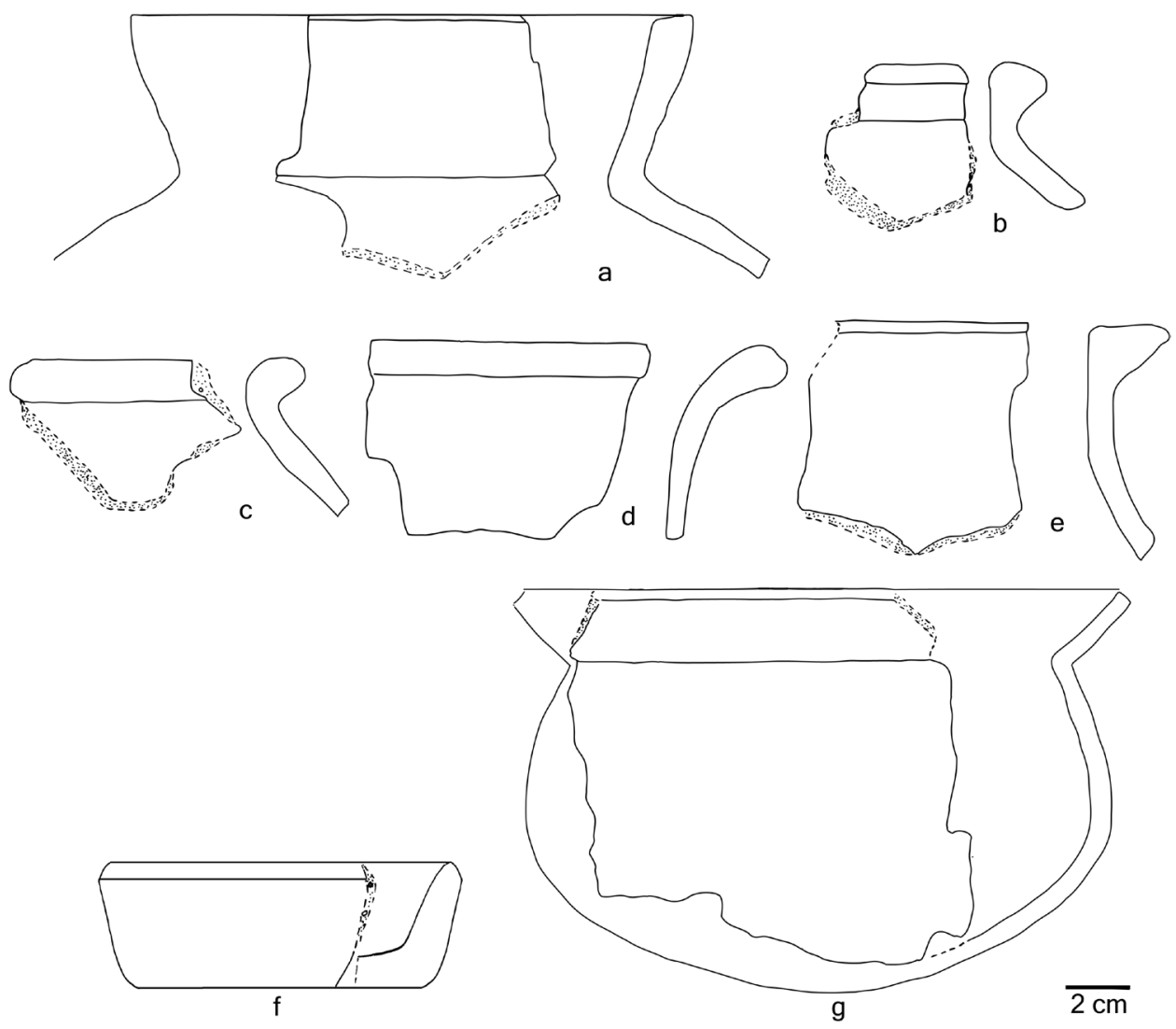

Fig. 4. Earthenware potsherds from the island of Cebu. Clockwise from left-a: AY11; b: AY15; c: AY13; d: AY14; e: AY12; f: AY10; and g: AY09.

Table 3. Elemental Groups Analyzed in the Study

\begin{tabular}{|c|c|c|c|c|c|c|c|c|}
\hline Alkali group & $\begin{array}{l}\mathbf{R b} \\
(<5 \%)\end{array}$ & $\begin{array}{l}\text { Cs } \\
(<5 \%)\end{array}$ & $\mathbf{K}$ & $\mathrm{Na}$ & Ba496 & & & \\
\hline Transition & $\begin{array}{l}\text { Sc } \\
(<5 \%)\end{array}$ & & $\begin{array}{l}\text { Hf } \\
(<5 \%)\end{array}$ & $\begin{array}{l}\mathbf{C r} \\
(<5 \%)\end{array}$ & $\begin{array}{l}\mathbf{F e} \\
(<5 \%)\end{array}$ & $\begin{array}{l}\text { Co } \\
(<5 \%)\end{array}$ & Zn & \\
\hline \multirow{2}{*}{$\begin{array}{l}\text { Other metals } \\
\text { and nonmetals }\end{array}$} & $\mathrm{Sb}$ & \multirow{2}{*}{$\begin{array}{l}\text { Th } \\
(<5 \%)\end{array}$} & & & & & & \\
\hline & As & & & & & & & \\
\hline $\begin{array}{l}\text { Rare earth } \\
\text { elements }\end{array}$ & $\begin{array}{l}\mathrm{Ce} \\
(<5 \%)\end{array}$ & $\begin{array}{l}\text { Sm } \\
(<5 \%)\end{array}$ & $\begin{array}{l}\mathbf{E u} \\
(<5 \%)\end{array}$ & $\mathbf{T b}$ & $\begin{array}{l}\mathbf{Y b} \\
(<5 \%)\end{array}$ & $\begin{array}{l}\mathbf{L u} \\
(<5 \%)\end{array}$ & $\begin{array}{l}\mathbf{L a} \\
(<5 \%)\end{array}$ & U228 \\
\hline
\end{tabular}

(see Figure 5). Figure 6 shows the bivariate plot, cluster dendrogram, and distance measures of the three groups, labeled A, B, and C in Figure 6. The confidence ellipse at 95 percent level grouped by each cluster further confirms the membership of these observations in the individual groups: the ellipses for each cluster do not overlap. Group A $(\mathrm{N}=4)$ is characterized by low concentrations of $\mathrm{Na}$ and Ba496. Impressionistic observations suggest that group $\mathrm{B}(\mathrm{N}=11)$ is characterized by 


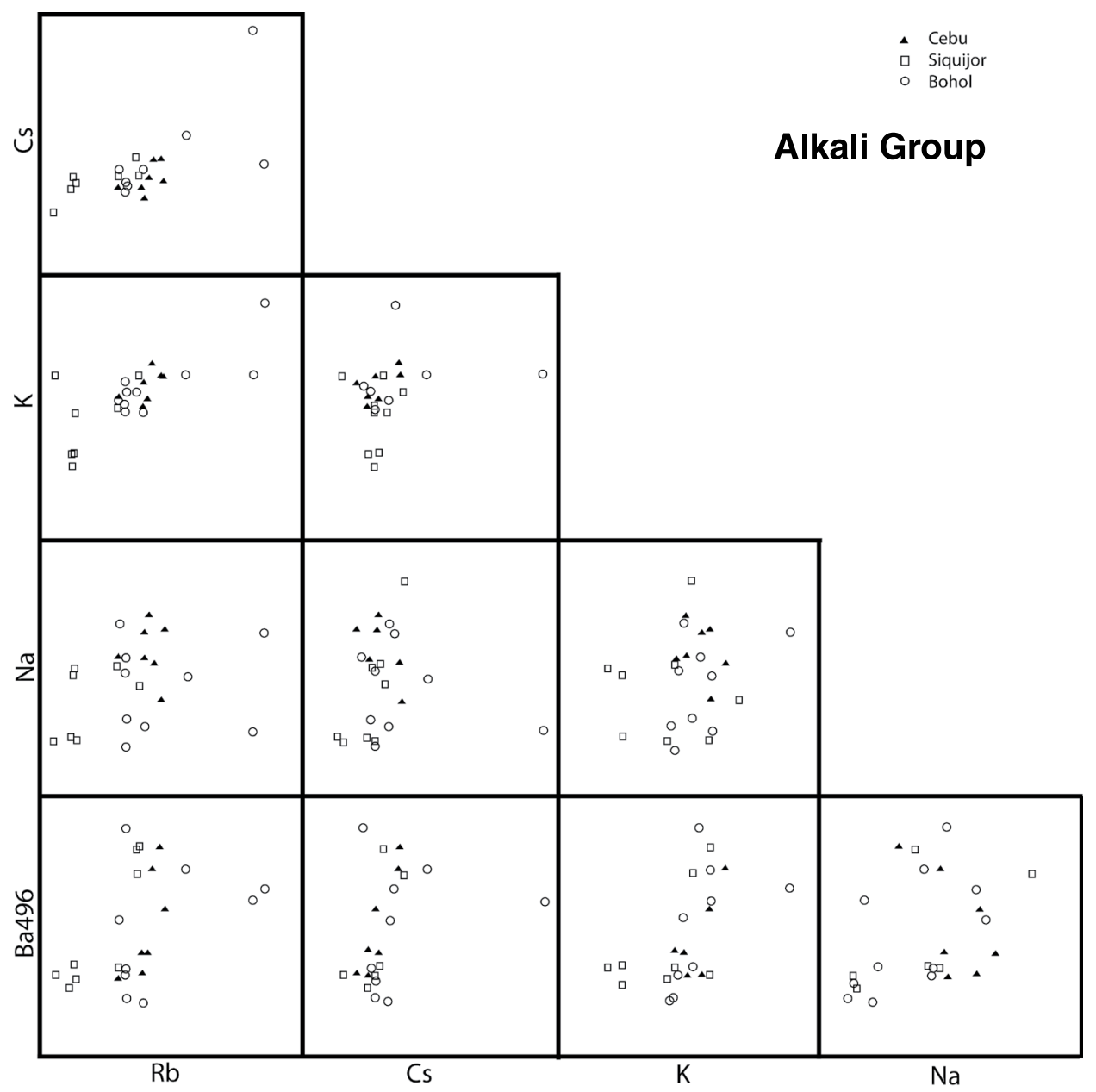

Fig. 5. Bivariate plots of A) alkali; B) transition metal; and C) rare earth elemental groups.

greater concentrations of $\mathrm{Na}$ and group $\mathrm{C}(\mathrm{N}=5)$ by greater concentrations of Ba496.

Another point meriting further consideration is within-group variation. Though CI intervals appear to enclose and separate cases into distinct groups (Figure 6), within-group variation was not consistent for the three groups. Within-group variation was relatively tight for group A and C but very loose for group B. This is due to the larger set of observations grouped into $\mathrm{B}$ in contrast to the four observations comprising $\mathrm{A}$ and $\mathrm{C}$ due to the cluster solution. Group B cluster solution may have been influenced significantly by the wide variation in the concentration of Ba496.

Further exploration of bivariate distributions did not show other elemental differentiation except for As. As appeared to be the only other element distinctive to Group A. Figure 7 shows Group A separation for As and $\mathrm{Na}$ and a 95 percent CI around the three clusters. The bivariate distribution for As indicates a greater tendency toward higher concentrations of As in Group A in contrast to the rest of the data set. 


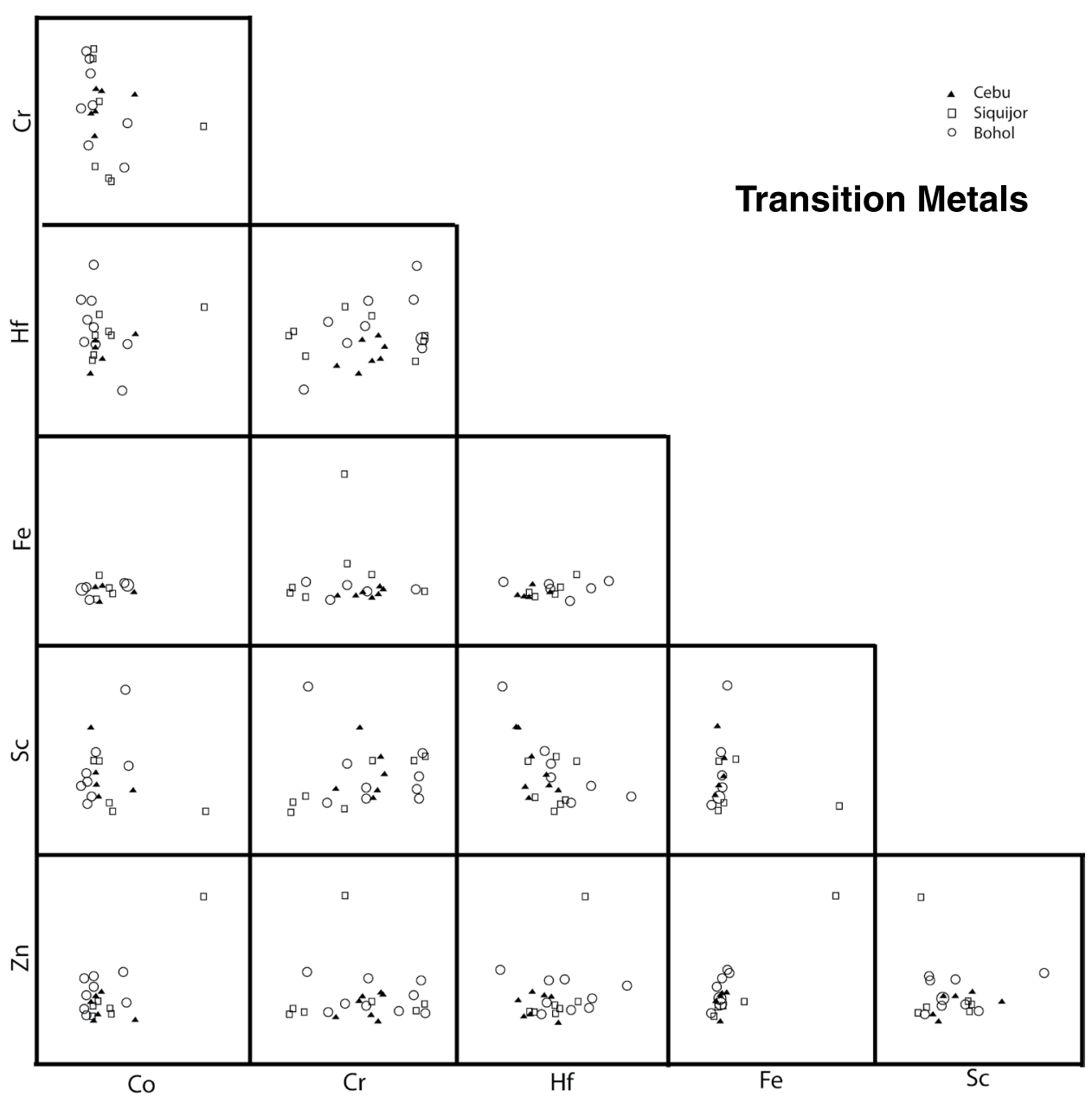

Fig. 5 (Continued)

\section{DISCUSSION}

The four samples from Group A (AY02, AY07, AY08, AY16) were all globular shaped pots associated with site C-11 on Bohol. Based on elemental concentrations alone, links between low concentrations of $\mathrm{Na}$ and high As with the area's geologic formation or stylistic differences cannot be directly established. We would expect, based on the abundance of feldspar materials in the region, that local materials would be enriched in alkali metals such as $\mathrm{Na}$ or $\mathrm{K}$. However, this expectation did not apply to Group A although other samples from the same site did yield higher concentrations of both elements (AY04 was extremely high in $\mathrm{K}$ and $\mathrm{Rb}$ ). In fact, other potsherds from site C-11 fell into Group B and C for Na, suggesting the heterogeneous nature of clay materials in this region and lending support to an observation Bacus had earlier proposed $(1995: 222)$. Examination of Group A potsherds under a low-powered $(30 \times)$ microscope showed the grains to be much smaller and more well rounded than other potsherds in the site sample. 


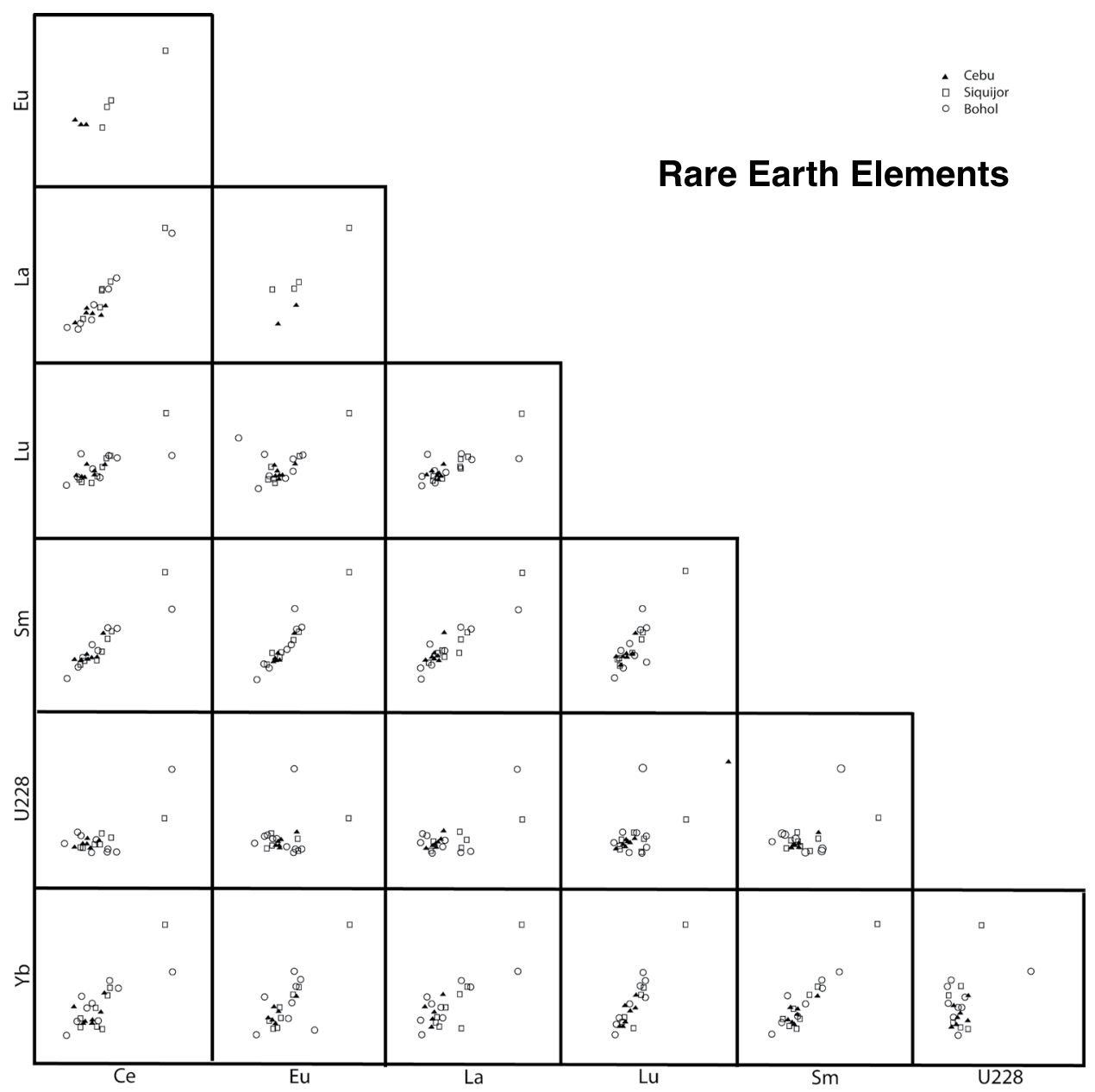

Fig. 5 (Continued)

The absence of separation on transition metals was another unanticipated finding given the limited distribution of andesitic materials on both Cebu and Bohol (Figure 5). Samples from sites downstream of dioritic regions did not yield the expected elemental concentrations $(\mathrm{Sc})$ of characteristic transition minerals. This may be due to the predominance of plagioclase and low concentration of amphiboles and olivines in the dioritic material. However, in the absence of greater sample size and information on the geological formation of drainage systems, these groupings represent preliminary observations on paste variability.

One observation deserving further discussion is the outlier (AY01), which is also a globular vessel from the C11 site. AY01 was excluded from the final clustering solution for Group A because of extremely high concentrations in rare earth elements (REE). Significant REE concentrations are unusual for this sample because sources of granite and basalt materials tend to be uncommon on the three islands. This expectation applied in most cases with the exception of AY01 (globular vessel) from C-11 and AY19 (rim of restricted vessel) from B-23 on Siquijor. In the absence of more precise 

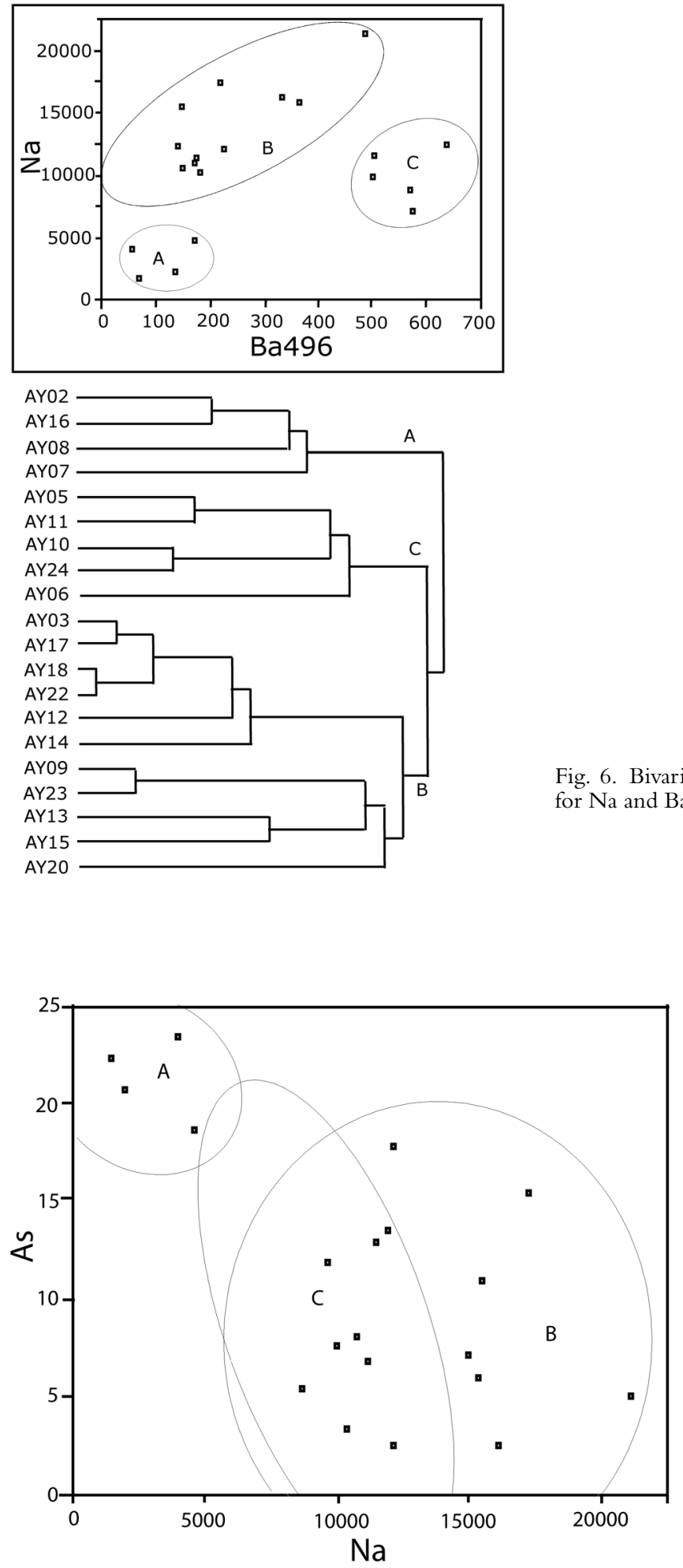

Fig. 6. Bivariate plot and cluster dendrogram for $\mathrm{Na}$ and $\mathrm{Ba} 496$.
Fig. 7. Bivariate plot for $\mathrm{Na}$ and As with 95 percent confidence interval. 
information on geological distributions in the central Visayan, it is difficult to specify the mineralogical sources for these REE enriched clays. AY01 was also one of two globular vessels with surface decoration, the exterior body being covered with a paddled cord design (see Figure 2b). Examination of AY01 and AY19 under a microscope at $30 \times$ showed poorly sorted grains that were highly angular. In addition, the paste was distinguished by inclusions of quartz and other dark materials. This observation, in contrast to the rounded grains of Group A potsherds containing few aplastic inclusions, suggests a tentative distinction between well-worked beach sand material perhaps of the coastal areas and angular grains that may be particular to interior regions of mafic materials.

Another outlier, AY21 (see Figure 3b), from C-74 on Siquijor also provides interesting results that suggest the presence of mafic materials in a region where no substantial dioritic formations are documented. AY21 is saturated with concentrations of $\mathrm{Fe}$, possibly indicative of a source of pyroxene minerals, silicates containing substantial amounts of Fe.

The inconclusive nature of the compositional analysis is likely attributed to problems with the small sample size. Specifically, the number of samples taken from each site was insufficient to represent the variability in the assemblage. Suggestions for future investigations should focus on taking larger samples from sites located within the same drainage system (Niziolek 2013) and also include a more comprehensive assessment of aplastic inclusions in the potsherds to determine other factors affecting elemental concentrations. Better chronological identification of the earthenware samples could also improve control over the sources of variability. However, since this study represents a pilot exploration of these archaeological materials using the INAA method, prior knowledge about compositional variability in earthenware was limited and an attempt was made to sample from a variety of contemporary sites to provide wider regional coverage.

\section{CONCLUSION}

The INAA results did not indicate significant group separations in elemental composition. Preliminary results showed that the most consistent grouping was characterized by low $\mathrm{Na}$ and $\mathrm{Ba} 496$, an unexpected association given the prevalence of feldspar materials in the geologic formation of the region. The outlier observations containing higher concentrations of elements associated with mafic materials also merit further consideration, but without greater knowledge of local geologic processes and drainage systems, it is difficult to identify the geographic origin of these materials.

The elemental information derived from this study represents an exploratory effort. The preliminary chemical profiles derived from the INAA analysis, with future involvement in the creation of a database, can be productive to investigations into these local trade networks.

\section{ACKNOWLEDGMENTS}

I would like to thank Leah Minc for providing me with training in INAA. Her patience in this learning process is much appreciated. Also, I thank Dr. Carla Sinopoli for access to the Guthe materials in the Museum of Anthropology. Any faults with this study are the responsibility of the author. 


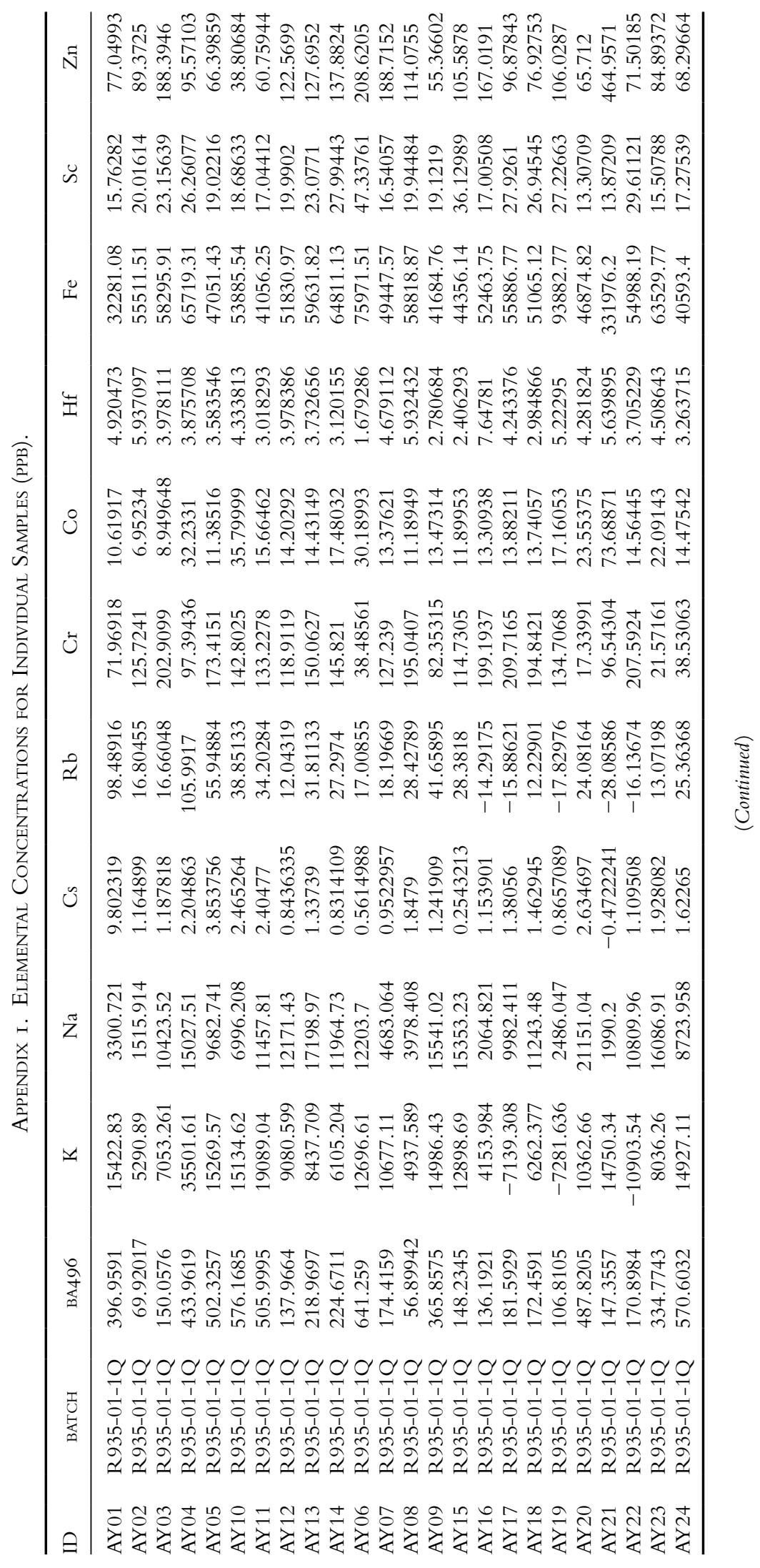




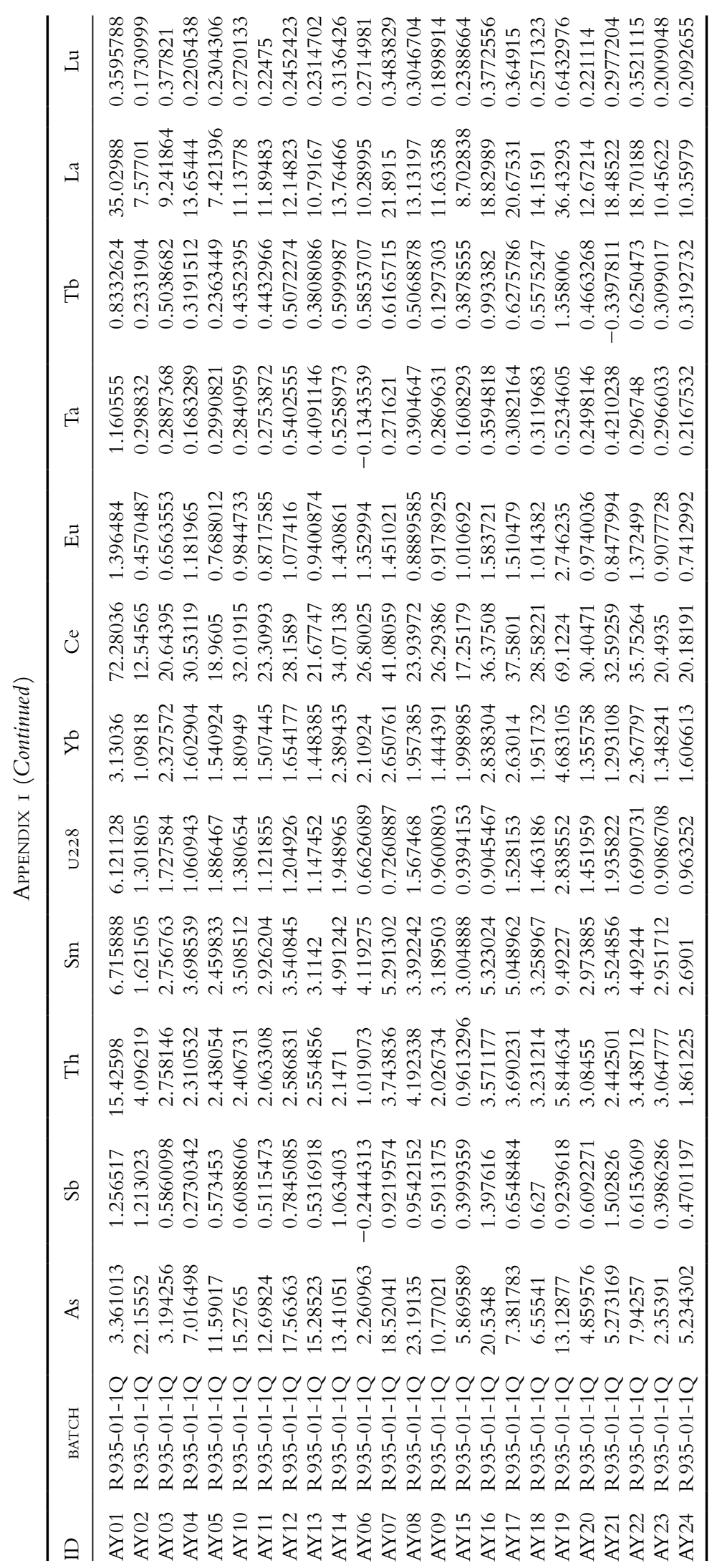




\section{NOTE}

1. Sites B23 and C74 on the island of Siquijor were included in order to achieve wider spatial coverage. Their relative contemporaneity with Bohol and Cebu sites is suggested by the presence of iron implements.

\section{REFERENCES CITED}

Bacus, Elisabeth

1995 Political economy and interaction: Late prehistoric polities in the central Philippine Islands. Ph.D. dissertation, University of Michigan.

Guthe, Carl

1929 Distribution of Sites Visited by the University of Michigan Philippine Expedition 1922-1925. Papers of the Michigan Academy of Science, Arts \& Letters. Vol. 10.

JUNKER, LAURA

1990 Long-distance trade and the development of sociopolitical complexity in Philippine chiefdoms of the first millennium to mid-second millennium A.D. (Volumes I-III). Ph.D. diss. University of Michigan.

1999 Raiding, Trading and Feasting. The Political Economy of Philippine Chiefdoms. Honolulu: University of Hawai'i Press.

Kruger, Paul

1971 Principles of Activation Analysis. New York: Wiley Interscience.

Muecke, Gunter, ED.

1980 Neutron Activation Analysis in the Geosciences: A Short Course Sponsored by the Mineralogical Association of Canada and Held Immediately Prior to their 1980 Annual Meeting, at Dalhousie University, Halifax, Nova Scotia, May 16th to 18th. Toronto: Mineralogical Association of Canada.

NizIOLEK, Lisa

2013 Earthenware production and distribution in the prehispanic Philippine polity of Tanjay: results from laser-ablation-inductively coupled plasma-mass-spectrometry (LA-ICP-MS). Journal of Archaeological Science 40:2824-2839.

Philippines Geological Survey Division

1963 Bureau of Mines in coordination with Board of Technical Survey and Maps.

SHENNAN, STEPHEN

1997 Quantifying Archaeology, 2nd ed. Edinburgh: Edinburgh University Press.

Smith, Warren Du Pre

1924 Geology and Mineral Resources of the Philippine Islands. Manila: Bureau of Printing.

\section{ABSTRACT}

This study undertakes an elemental compositional analysis of Philippine earthenware vessels from the Guthe collection using Instrumental Neutron Activation Analysis (INAA). Unlike foreign trade ceramics, earthenware vessels were locally produced goods but which also played a part in the development of Philippine chiefdoms as an item traded between inland and coastal groups. Thus, the detection of compositional groups within earthenware vessels may help identify patterns of production and exchange. It is also hoped that the results from this pilot study can contribute to the future development of an elemental database for earthenware vessels. KeYwords: Philippines, earthenware, exchange, Instrumental Neutron Activation Analysis. 